\title{
Dysmorphic features in offspring of alcoholic mothers
}

\author{
I Autti-Rämö, E Gaily, M-L Granström
}

\begin{abstract}
The frequencies of 60 minor physical anomalies and various craniofacial measurements in 52 children with alcohol exposure of various durations in utero were determined and compared with 48 non-exposed healthy children at a mean age of 27 months. Compared with nonexposed children a significantly higher total minor physical anomaly count was observed in those children exposed prenatally to alcohol throughout pregnancy. Binge drinking was not associated with an increased minor physical anomaly count. During the first year of life facial features were judged according to subjective impression: 10 children had typical facial features of fetal alcohol syndrome (FAS) and 19 children were judged to have possible fetal alcohol effects on their face. Only six of them fulfilled the strict craniofacial criteria for diagnosis of FAS at the age of 27 months. Our results stress the importance of recognising also the subtle dysmorphic facial features associated with prenatal alcohol exposure: 22 of $29(76 \%)$ of exposed children judged to have typical or possible features of FAS during the first year showed signs of central nervous system dysfunction at the age of 27 months.
\end{abstract}

When Jones and his colleagues reported the association between exposure to alcohol in utero and aberrant morphogenesis, the most frequent minor physical anomalies observed were short palpebral fissure, altered palmar crease patterns, maxillary hypoplasia, and epicanthus. ${ }^{12}$ Since then a considerable variety of minor anomalies has been reported. ${ }^{3-8}$ When the Fetal Alcohol Study Group of the Research Society on Alcoholism (RSA) set the minimum criteria for the diagnosis of fetal alcohol syndrome (FAS) only minor physical anomalies of the facial area were included. ${ }^{9}$ In addition to growth retardation and dysfunction of the central nervous system, a diagnosis of FAS requires at least two of the following three craniofacial signs to be present: (i) microcephaly, (ii) microophthalmia and/or short palpebral fissure, and (iii) hypoplastic philtrum with thin upper lip and flattening of the maxillary area.

In addition to the widely used definition of the RSA, Majewski ${ }^{10}$ and Vitez et al ${ }^{11}$ have presented two different semiquantitative scoring systems for the probability and severity of FAS, both of which include the RSA criteria. Majewski included 23 minor and major anomalies in his 29 item scoring system and Vitez et al 45 malformations in their 51 item scoring system.
The first aim of the present study was to analyse the occurrence of minor physical anomalies in children exposed to alcohol in utero and to compare these with non-exposed children in order to see whether the duration of alcohol exposure was associated with the amount or type of minor physical anomaly. The second aim was to decide whether the subjective assessment of facial features during the first year of life suggestive of fetal alcohol exposure can be affirmed by an independent examination during the third year of life. The third aim was to study whether judgment based on a subjective impression can be of clinical value in diagnosing children with possible fetal alcohol effects.

\section{Subjects}

Eighty two children exposed to alcohol in utero were followed up prospectively at the Children's Castle Hospital, Helsinki. The mothers had entered the study in their second trimester and were followed up at two to four week intervals at a special outpatient clinic for pregnant women at the Helsinki University Central Hospital. $^{12}$ At each visit the mothers were informed of the harmful effects of fetal alcohol exposure and were encouraged to stop their drinking. The mothers' reports on their drinking, use of drugs, and smoking were recorded for each interval between visits. Alcohol consumption was assessed according to Rosett et $a l$ as heavy if it exceeded $140 \mathrm{~g}$ per week or 630 g per month. ${ }^{13}$ Children were divided into three groups according to the recorded data. Group I consisted of children exposed to heavy alcohol consumption during the first trimester only $(n=29)$. Group II consisted of children exposed to heavy alcohol consumption during the first and second trimesters $(n=27)$. Group III consisted of children exposed to heavy alcohol consumption throughout pregnancy $(n=26)$. Eight mothers reported mainly moderate (24-140 g per week) but regular alcohol consumption during their first trimester, and they were included in group I. The pattern of drinking was classified as either binge drinking (five or more drinks on one occasion) or not.

After birth the children were systematically followed up at the Children's Castle Hospital, the examiners being unaware of exposure status. ${ }^{14}{ }^{15}$ At the fifth assessment at a mean age of 27 months the developmental levels of 60 (73\%) exposed children were assessed by a psychologist and a speech therapist. ${ }^{16}$ Fifty two $(63 \%)$ of these children underwent a thorough assessment of their dysmorphic features, which were recorded by one of the authors (EG); 51 of 
them were seen at least once during their first year of life.

The non-exposed group was composed of 48 children who were exposed only to vitamins, iron substitution, and non-teratogenic antibiotics. Sixteen children were born to abstinent mothers who had been checked regularly during pregnancy at the outpatient clinic for alcohol consuming pregnant women. ${ }^{17}$ Thirty two children were born to abstinent low social class women collected from a large prospective population based study on alcohol consumption during pregnancy. ${ }^{18}$

\section{Methods}

During the first year of life the facial features of the child were subjectively assessed as normal, possible fetal alcohol effects (FAE face), typical FAS face, and abnormal not resembling FAS by one of us (IA-R).

At a mean age of 27 months (24-36 months), the minor physical anomalies of the children were systematically recorded according to a checklist of 60 minor physical anomalies (table 1) by one of us (EG). The checklist was based on the dysmorphology patterns presented by Smith ${ }^{19}$ and modified according to the reports on dysmorphic features in children exposed to alcohol in utero. ${ }^{1-411}$ Fingertip patterns were classified according to Penrose. ${ }^{20}$ Three or more arches was regarded as abnormal, as in a previous Finnish study. ${ }^{21}$

The frequencies of all the features given in table 1 were computed for the exposed and nonexposed groups. According to Marden et $a^{22}$ and Leppig et al, ${ }^{23}$ only those features found in less than $5 \%$ of the 48 non-exposed children were regarded as minor physical anomalies in this study (because of the small number of nonexposed children the limit was changed from the original $4 \%$ to $5 \%$ ). Of those features omitted from further analysis dysmorphic ears (three of non-exposed and nine of exposed children, $p<0.05$ ) and hypoplastic philtrum (three of non-exposed and nine of exposed children, $p<0 \cdot 05$ ) were seen significantly more often in the exposed children. For the analysis of data the number of minor physical anomalies in each child was used as the minor physical anomaly score.

Table 1 Checklist of 60 minor anomalies. ${ }^{*}$ Those observed in more than $4 \%$ of the non-exposed children

\begin{tabular}{|c|c|c|}
\hline $\begin{array}{l}\text { Abnormal head shape } \\
\text { Prominent forehead* } \\
\text { Abnormal suturae } \\
\text { Midfacial hypoplasia } \\
\text { Synophrys } \\
\text { Upward slanting eyes } \\
\text { Downward slanting eyes } \\
\text { Epicanthus (deeply covered } \\
\text { upper and lower lip joint) } \\
\text { Hypertelorism** } \\
\text { Strabismus } \\
\text { Ptosis } \\
\text { Low nasal bridge } \\
\text { High nasal bridge } \\
\text { Short nose* } \\
\text { Anteverted nostrils } \\
\text { Long philtrum } \\
\text { >3 Arches (dermatoglyphics } \\
\text { of both hands) } \\
\text { Brachydactyly } \\
\text { Clinodactyly } \\
\text { Arachnodactyly }\end{array}$ & $\begin{array}{l}\text { Hypoplastic fingernails } \\
\text { (fingers or toes) } \\
\text { Hypoplastic phalanges* } \\
\text { Digital thumb } \\
\text { Syndactyly between fingers } \\
\text { Syndactyly between I } \\
\text { and II toes } \\
\text { Wide gap between I } \\
\text { and II toes } \\
\text { Toes overlapping } \\
\text { III toe as long as or longer } \\
\text { that II toe* } \\
\text { Hirsutism } \\
\text { Haemangiomas* } \\
\text { Hypopigmentation } \\
\text { Hyperpigmentation } \\
\text { Pectus carinatum } \\
\text { Joint contractures } \\
\text { Abnormal elasticity of skin } \\
\text { Non-descended testes } \\
\text { Hypospadia } \\
\text { Hypoplastic philtrum* }\end{array}$ & $\begin{array}{l}\text { Thin upper lip } \\
\text { Thick upper lip* } \\
\text { Prominent upper lip } \\
\text { Small mouth } \\
\text { Wide mouth: } \\
\text { Maxillar hypoplasia } \\
\text { Mandibular hypoplasia } \\
\text { Posteriorly rotated ears } \\
\text { Dysmorphic ears": } \\
\text { Low set ears } \\
\text { Adherent ears } \\
\text { Outset ears } \\
\text { Asymmetric ears } \\
\text { High arch palate } \\
\text { Lateral ridges } \\
\text { Abnormally furrowed tongue } \\
\text { Abnormal teeth } \\
\text { Low set hair } \\
\text { Abnormal hair } \\
\text { Simian crease: } \\
\text { Inguinal hernia } \\
\text { Umbilical hernia }\end{array}$ \\
\hline
\end{tabular}

In addition to clinical inspection the following exact measurements were taken at the 27 month assessement: (a) the largest occipitofrontal circumference (metal band), (b) philtrum length (1 $\mathrm{mm}$ ruler), (c) interpupillary distance $(1 \mathrm{~mm}$ ruler), (d) distance between inner canthi $(1 \mathrm{~mm}$ ruler), (e) distance between outer canthi $(1 \mathrm{~mm}$ ruler), and (f) distance from upper lip to inner canthus ( $1 \mathrm{~mm}$ ruler).

The head circumference was tranformed into SD scores of Finnish normative data. Mean palpebral length was calculated by subtracting the distance between the inner canthi from the distance between the outer canthi and dividing the result by two. Palpebral length below $-2 S D$ of our non-exposed children was regarded as short.

For the analysis of relationships between the facial measurements all ratios were calculated. The following ratios will be presented in this paper: (a) distance between inner canthi/ distance between outer canthi, (b) philtrum length/distance from upper lip to inner canthi, (c) philtrum length/distance between outer canthi, and (d) distance from upper lip to inner canthi/distance between out canthi.

The development level of the children was assessed by a psychologist using the manual for the Bayley scales of infant development ${ }^{24}$ and by a speech therapist using the manual for the Reynell developmental language scales (verbal comprehension A). ${ }^{1625}$

\section{STATISTICS}

The non-parametric Kruskal Wallis one way analysis of variance (3S) was used to compare the differences in the minor physical anomaly scores between the various groups; between two groups the Mann-Whitney U test was used. The difference in occurrence of two or more minor physical anomalies between the groups was tested using the $\chi^{2}$ analysis and linear trend test. One way analysis of variance (ANOVA) was used to compare the morphological measurements between the groups; in pairwise analysis the Bonferroni correction was used. These measurements were also adjusted for the head circumference (ANCOVA). Differences in the occurrences of single minor physical anomalies between non-exposed and exposed children were tested for significance using Fisher's exact test for fourfold tables. A p value below 0.05 was considered significant. The computations were made using the Biomedical Data Package (BMDP). ${ }^{26}$

This study was accepted by the ethical committee of our hospital.

\section{Results}

The facial features of the 51 children during the first year of life are shown in table 2 . All non-

Table 2 Facial features of 51 children seen during first year of life

\begin{tabular}{lllll}
\hline & $\begin{array}{l}\text { Normal } \\
(n=19)\end{array}$ & $\begin{array}{l}\text { Possible } \\
F A E \\
(n=19)\end{array}$ & $\begin{array}{l}\text { Typical } \\
F A S \\
(n=10)\end{array}$ & $\begin{array}{l}\text { Abnormal not } \\
\text { resembling FAS } \\
(n=3)\end{array}$ \\
\hline Group I & 9 & 3 & 1 & 3 \\
Group II & 8 & 9 & 1 & - \\
Group III & 2 & 7 & 8 & - \\
\hline
\end{tabular}


exposed children were judged to have a normal looking face.

At the 27 month dysmorphic assessment we saw a significant difference between the groups in minor physical anomaly scores (table 3). Those children exposed to heavy alcohol concentrations throughout pregnancy had significantly higher minor physical anomaly scores than the children belonging to any other group (group III/any other group, $\mathrm{p}<0.01$ ). There was a significant linear trend in those with two or more minor physical anomalies towards longer exposure time. Binge drinking was not connected with an increased minor physical anomaly count. No typical patterns of minor physical anomalies were formed.

Head growth was significantly affected by the duration of fetal alcohol exposure (table 4) but no differences in facial measurements were found between the groups. All horizontal distances in the eye region were significantly dependent on head circumference $(p<0.001$ for distance between outer canthi, interpupillary distance, and palpebral size; $p=0.002$ for distance between inner canthi). Vertical distances measured on the face were not dependent on the head circumference. The various relationships between the facial measurements showed no significant differences between the groups.

The single facial features mandatory for diagnosis of FAS $^{9}$ were observed more often in the exposed children; short palpebral fissure only in exposed children (table 5). No limit based on the relationships between horizontal measurements could be set to identify short palpebral fissure. The criteria of Vitez et al for short palpebral fissure-distance between inner

Table 3 Minor physical anomalies recorded per child

\begin{tabular}{|c|c|c|c|c|c|c|c|c|c|}
\hline \multirow[t]{2}{*}{ Group } & \multirow{2}{*}{$\begin{array}{l}\text { No of } \\
\text { children }\end{array}$} & \multicolumn{7}{|c|}{ No of minor physical anomalies } & \multirow{2}{*}{$\begin{array}{l}\text { No }(\%) \text { with } \geqslant 2 \text { minor } \\
\text { physical anomaliest }\end{array}$} \\
\hline & & 0 & 1 & 2 & 3 & 4 & 5 & 6 & \\
\hline $\begin{array}{l}\text { Non-exposed } \\
\text { Group I } \\
\text { Group II } \\
\text { Group III }\end{array}$ & $\begin{array}{l}48 \\
16 \\
19 \\
16^{*}\end{array}$ & $\begin{array}{r}26 \\
7 \\
4\end{array}$ & $\begin{array}{r}13 \\
5 \\
8 \\
1\end{array}$ & $\begin{array}{l}5 \\
3 \\
3 \\
6\end{array}$ & $\begin{array}{l}4 \\
1 \\
3 \\
2\end{array}$ & $\begin{array}{l}1 \\
2\end{array}$ & 3 & 2 & $\begin{array}{r}9(19) \\
4(25) \\
7(37) \\
15(94)\end{array}$ \\
\hline
\end{tabular}

*One child excluded because of insufficient data.

Kruskal-Wallis between groups: $F=31 \cdot 25, p<0 \cdot 0001$.

$t \chi^{2}: F=30.43, p<0.001$; linear trend: $F=24.26, p<0.001$ canthi over one third of the distance between outer canthi-defined all the non-exposed children to have short palpebral fissure. ${ }^{11}$ Hypoplastic philtrum and thin upper lip were observed together only in exposed children. The craniofacial criterias set by the RSA were fulfilled in two (10\%) group II children and four (24\%) group III children.

The six children meeting either two or three craniofacial criteria set by the $\mathrm{RSA}^{9}$ had significantly smaller head size, interpupillary distance, distance between the outer canthi, and palpebral size (table 6). After adjustment for head circumference the mean values were smaller in the FAS group, but a significant difference was observed only in palpebral fissure length. The actual philtrum length was not significantly higher in FAS children but the ratio between philtrum length and distance from upper lip to inner canthi and the ratio between philtrum length and distance between the outer canthi were significantly higher in children who met the craniofacial criteria for FAS. However, contrary to Vitez et al no limit for the ratios of vertical distances could be given to define long philtrum. ${ }^{11}$ When those features included in the craniofacial criteria for FAS were excluded from the minor physical anomaly score, these six children still had a significantly higher score (range 1-5) than non-exposed children (range $0-3)(\mathrm{p}<0.01)$.

In order to evaluate the relationship between a subjective assessment during the first year of life and an assessment at 27 months based on strict criteria, the results of the 51 exposed children seen at both assessments were compared (table 7). All those six children who met at least two craniofacial criteria for diagnosis of FAS were judged to have a possible FAE or typical FAS face during their first year of life. However, four of the 10 children considered to have typical FAS face during their first year of life met no craniofacial criteria for FAS diagnosis at the 27 month assessment. At the 27 month assessment the 10 children assessed to have a typical FAS face during their first year of life had significantly smaller head circumference and horizontal measurements (table 6). The differences in horizontal measurements did not remain significant after adjustment for head

Table 4 Results of the growth and morphological measurements. Results are mean (SEM); the numbers of children excluded because of unreliable data are in parentheses

\begin{tabular}{|c|c|c|c|c|}
\hline & $\begin{array}{l}\text { Non-exposed } \\
(n=48)\end{array}$ & $\begin{array}{l}\text { Group } I \\
(n=16)\end{array}$ & $\begin{array}{l}\text { Group } I I \\
(n=19)\end{array}$ & $\begin{array}{l}\text { Group III } \\
(n=I 7)\end{array}$ \\
\hline $\begin{array}{l}\text { Head circumference (SD) } \\
\text { Height (SD) } \\
\text { Relative weight (\%) } \\
\text { Distance between inner canthi (mm) } \\
\text { Adjusted for head circumference } \\
\text { Distance between outer canthi (mm) } \\
\text { Adjusted for head circumference } \\
\text { Interpupillary distance (mm) } \\
\text { Adjusted for head circumference } \\
\text { Palpebral fissure (mm) } \\
\text { Adjusted for head circumference } \\
\text { Philtrum length (mm) } \\
\text { Upper lip to inner canthus (mm) } \\
\text { Inner canthi/outer canthi } \\
\text { Philtrum/upper lip to inner canthus } \\
\text { Philtrum/outer canthi } \\
\text { Upper lip to inner canthus/distance } \\
\text { between outer canthi }\end{array}$ & $\begin{array}{c}0 \cdot 1(0 \cdot 15) \\
-0 \cdot 37(0 \cdot 12) \\
4 \cdot 26(1 \cdot 49) \\
\text { (2) } 26 \cdot 02(0 \cdot 32) \\
25 \cdot 75(0 \cdot 33) \\
\text { (2) } 69 \cdot 48(0 \cdot 42) \\
68 \cdot 9(0 \cdot 71) \\
\text { (1) } 45 \cdot 87(0 \cdot 32) \\
45 \cdot 44(0 \cdot 32) \\
\text { (2) } 21 \cdot 73(0 \cdot 14) \\
21 \cdot 58(0 \cdot 16) \\
14 \cdot 12(0 \cdot 37) \\
\text { (3) } 42 \cdot 33(0 \cdot 32) \\
0 \cdot 374(0.003) \\
0 \cdot 336(0.007) \\
\\
0 \cdot 204(0 \cdot 005)\end{array}$ & $\begin{array}{l}-0.005(0 \cdot 24) \\
-0 \cdot 4(0 \cdot 27) \\
1 \cdot 49(2 \cdot 29) \\
26 \cdot 06(0.78) \\
25.94(0 \cdot 55) \\
69 \cdot 75(0.93) \\
69 \cdot 5(0 \cdot 71) \\
45 \cdot 94(0.62) \\
45 \cdot 79(0.53) \\
21 \cdot 84(0 \cdot 26) \\
21 \cdot 78(0 \cdot 27) \\
14 \cdot 87(0 \cdot 54) \\
41.99(0 \cdot 95) \\
0 \cdot 373(0 \cdot 008) \\
0.354(0.009) \\
0.2213(0.008)\end{array}$ & 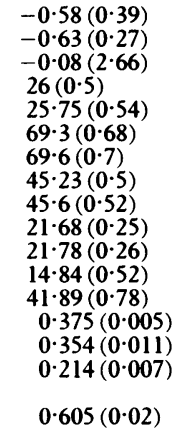 & $\begin{array}{cc} & -1.494(0.34)^{* * *} \\
& -1.45(0.25)^{* * *} \\
-10.46(1.40)^{* * * *} & -10 \\
\text { (1) } & 25.5(0.46) \\
& 26.09(0.58) \\
\text { (1) } & 67.56(0.95) \\
& 68.8(0.74) \\
\text { (1) } & 44.31(0.63) \\
& 45.04(0.56) \\
\text { (1) } & 21.03(0.4) \\
& 21.35(0.3) \\
(1) & 14.62(0.364) \\
\text { (1) } & 42.2(0.55) \\
& 0.378(0.006) \\
& 0.347(0.009) \\
& 0.217(0.007) \\
& 0.626(0.011)\end{array}$ \\
\hline
\end{tabular}

$\mathrm{p}<0.001$ compared with non-exposed children. 
Table 5 Single facial features mandatory for diagnosis of FAS

\begin{tabular}{|c|c|c|c|c|c|}
\hline & $\begin{array}{l}\text { Non-exposed } \\
(n=48)\end{array}$ & $\begin{array}{l}\text { All exposed } \\
(n=52)\end{array}$ & $\begin{array}{l}\text { Group I } \\
(n=16)\end{array}$ & $\begin{array}{l}\text { Group II } \\
(n=19)\end{array}$ & $\begin{array}{l}\text { Group III } \\
(n=I 7)\end{array}$ \\
\hline $\begin{array}{l}\text { Palpebral fissure }<-2 S D \\
\text { Hypoplastic philtrum } \\
\text { Thin upper lip }\end{array}$ & $\begin{array}{l}0 \\
3 \\
1\end{array}$ & $\begin{array}{c}6^{*} \\
9 \\
10^{*}\end{array}$ & $\begin{array}{l}1 \\
1 \\
1\end{array}$ & $\begin{array}{l}1 \\
1 \\
2\end{array}$ & $\begin{array}{l}4 \\
7 \\
7\end{array}$ \\
\hline
\end{tabular}

${ }^{*} \mathbf{p}<0.05$ all exposed $v$ non-exposed.

Table 6 Facial measurements of exposed children meeting two or three craniofacial criteria at the 27 month assessment in the first column and of exposed children subjectively assessed to have a FAS face during their first year of life in the second column. Results are mean (SEM) and are compared with those for non-exposed children (see table 4)

\begin{tabular}{|c|c|c|}
\hline & $\begin{array}{l}27 \text { month assessment: } \\
\text { FAS face }(n=6)\end{array}$ & $\begin{array}{l}\text { First year assessment } \\
\text { FAS face }(n=10)\end{array}$ \\
\hline $\begin{array}{l}\text { Head circumference (SD) } \\
\text { Distance between outer canthus (mm) } \\
\text { Adjusted for head circumference } \\
\text { Interpupillary distance (mm) } \\
\text { Adjusted for head circumference } \\
\text { Palpebral fissure (mm) } \\
\text { Adjusted for head circumference } \\
\text { Philtrum length (mm) } \\
\text { Upper lip to inner canthus (mm) } \\
\text { Inner canthi/outer canthi } \\
\text { Philtrum/upper lip to inner canthus } \\
\text { Philtrum/outer canthi } \\
\text { Upper lip to inner canthus/distance } \\
\text { between outer canthi }\end{array}$ & $\begin{array}{l}-2.58(0.35)^{* * *} \\
65.0(1.05)^{* *} \\
67.3(1.38) \\
43.00(0.73)^{*} \\
44.6(0.95) \\
19.92(0.69)^{* * * *} \\
20.45(0.52)^{* *} \\
16(0.58) \\
41 \cdot 27(1.08) \\
0.39(0.009) \\
0.39(0.016)^{* *} \\
0.25(0.009)^{* *} \\
0.64(0.027)\end{array}$ & $\begin{array}{l}-2.03(0.43)^{* * * *} \\
65.4(0.7)^{* * *} \\
66.47(0.96) \\
42.9(0.5)^{* * * *} \\
43.56(0.65) \\
20.4(0.51)^{* * * *} \\
20.68(0.38) \\
14.9(0.64) \\
42.9(0.43) \\
0.38(0.43) \\
0.35(0.012) \\
0.23(0.011) \\
0.66(0.012)^{* * *}\end{array}$ \\
\hline
\end{tabular}

Table 7 Comparison of a subjective assessment of facial features during the first year of life and an objective assessment at 27 months of age

\begin{tabular}{lllll}
\hline At 27 months of age & \multicolumn{4}{l}{ Assessment of facial features during the first year of life } \\
\cline { 2 - 5 } & Normal $(n=19)$ & $F A E(n=19)$ & $F A S(n=10)$ & Atypical $(n=3)$ \\
\hline Microcephalia & 1 & 3 & 4 & 0 \\
Short palpebral fissure & 1 & 1 & 4 & 0 \\
Hypoplastic philtrum & 2 & 5 & 2 & 0 \\
Thin upper lip & 3 & 3 & 4 & 0 \\
Two or three craniofacial criteria & 0 & 3 & 3 & 0 \\
\hline
\end{tabular}

circumference. The restricted growth of the head meant that these 10 children had a long midface in relation to horizontal measurements. The number of minor physical anomalies was significantly higher in children judged to have FAE features $(p<0.05)$ and FAS features $(\mathrm{p}<0.01)$ compared with the non-exposed children.

Thirty two (62\%) of the 52 exposed children who had undergone a thorough dysmorphic study showed poor performance in the developmental tests used at the 27 month assessment. All those six children that met the craniofacial criteria for FAS in the dysmorphic study performed under the $-2 S D$ level in the development tests. All 10 children judged to have typical FAS face during their first year of life, 12/19 judged to have possible FAS face, 1/3 judged to have abnormal face not resembling FAS, and only $8 / 29$ judged to have normal looking face performed poorly in the used developmental tests $(\mathrm{p}<0.05)$.

\section{Discussion}

There is no consensus regarding the specific number and types of minor physical anomalies that should be included in a dysmorphological assessment. Studies on dysmorphology in children with alcohol exposure in utero have used varying, self constructed minor dysmorphology scales. ${ }^{27} 28$ The 18 item weighted minor physical anomaly scale of Waldrop and Halverson ${ }^{29}$ has been used in several studies on children with behavioural problems. ${ }^{30-32}$ It was not accepted for this study as none of the facial features mandatory for FAS diagnosis ${ }^{9}$ are included and several of its items are observed in over $4 \%$ of Finnish children. ${ }^{21}$ For this study we tried to form a clinically applicable and representative minor physical anomaly scale that would include those minor physical anomalies reported in children exposed to alcohol in utero.

A significantly higher total minor physical anomaly count was observed only in those children exposed to alcohol throughout pregnancy, which is in conflict with the results of Day et $a l^{27}$ but supports the results of Tennes and Blackard. ${ }^{28}$ Contrary to earlier studies ${ }^{10} 11$ we were not able to form a scoring system for various minor physical anomalies or set limits for facial relationships to identify fetal alcohol effects.

Features regarded as minor physical anomalies may be formed by several mechanisms: they can represent true malformations, disruptions, deformations, or dysplasia. ${ }^{33} 34$ True malformations arise in the first trimester during the period of organogenesis, while other types of minor physical anomaly may be formed later during gestation. As a teratogen alcohol could interfere with an originally normal developmental process causing disruption at any stage of gestation. Frias $e t$ al has postulated that some observed features regarded as malformations are secondary to restricted growth of the brain. ${ }^{35}$ Fetal hypomobility during periods of alcohol exposure in utero may also cause various deformations. Our results suggest that alcohol should be regarded as a teratogen that leads to dysmorphic features, especially during the time of rapid intrauterine growth. The inconsistent drinking patterns, one to 20 drinks per day, may explain why binge drinking was not associated with a higher minor physical anomaly count in this study.

Short palpebral fissure was a constant feature in the first children with FAS reported. ${ }^{4}$ Jones et al have claimed that the short palpebral fissure in children with FAS is secondary to decreased growth of the eye. ${ }^{36}$ This has been contradicted by Bierich $e t a l^{37}$ and Fuchs $e t a l .^{38}$ Stengel-Rutkowski et al have shown that normally the outer canthi lateralise more than the inner canthi with increasing age. ${ }^{39}$ In our children the distance between the outer canthi was more dependent on head circumference than the distance between the inner canthi. Our results suggest that the short palpebral fissure seen in children exposed to alcohol in utero is mainly secondary to impaired head growth, although the possible additive influence of restricted growth of the eye could not be excluded.

The subjective assessment of facial features typical of FAS during the first year of life could not be confirmed in all cases when strict criteria were used over one year later. However, those 10 children judged to have a typical FAS face 
during their first year of life had significantly more minor physical anomalies than our nonexposed children, impaired head growth, and relatively long midface at the 27 month assessment as also observed by Clarren et al. ${ }^{40}$ Subjective assessment of FAE or FAS features in early infancy recognised also most of those children that had been exposed prenatally to alcohol in amounts that had affected their central nervous system.

The craniofacial criteria of the $\mathrm{RSA}^{9}$ for FAS were too strict to identify those children with clear central nervous system dysfunction but no typical FAS face. ${ }^{16}$ It is important to learn to recognise various minor physical anomalies and subtle changes in facial relations when children with disorders of central nervous system or growth retardation of unknown aetiology are examined.

Supported by the Finnish Foundation for Alcohol Studies, Research Department of the Rinnekoti Foundation, Arvo and Lea Ylppö Foundation.

1 Jones KL, Smith DW, Ulleland CN, Streissguth AP. Pattern of malformation in offspring of chronic alcoholic mothers. Lancet 1973; ;:1267-71.

2 Jones KL, Smith DW. Recognition of the fetal alcohol syndrome in eary infancy. Lancet 1973;ii:999-1001.

3 Majewski F, Bierich JR, Löser H, Michaelis R, Leiberf B, Bettecken F. Zur Klinik und Pathogenese der Alkoholembryopathie. Münchener Medizinische Wochenschrift 1976 118:1635-42.

4 Hanson JW, Jones KL, Smith DW. Fetal alcohol syndrome-experience with 41 patients. $\mathscr{f} A M A$ 1976;235: 1458-60.

5 Halliday HL, McM Reid M, McClure G. Results of heavy drinking in pregnancy. $B r \mathcal{F}$ Obstet Gynaecol 1982;89: $892-5$.

6 Robinson GC. Conry JL, Conry RF. Clinical profile and prevalence of fetal alcohol syndrome in an isolated prevalence of fetal alcohol syndrome in an isolated community in

7 Mills JL, Graubard BI. Is moderate drinking during pregnancy associated with an increased risk for malformation.

8 Graham JM, Hanson JW, Darby BL, Barr HM, Streissguth AP. Independent dysmorphology evaluations at birth and 4 years of age for children exposed to varying amounts of alcohol in utero. Pediatrics 1988;81:772-8.

9 Rosett HL. A clincal perspective of the fetal alcohol syndrome. Alcohol Clin Exp Res 1980;4:119-22.

10 Majewski F. Ueber schaedigende Einflusse des Alkohols auf die Nachkommen. Nervenartz 1978:49:410-6.

11 Vitez M, Koranyi G, Gönczy E, Rudas T, Czeizel A. A semiquantitative score system for epidemiologic studies of fetal alcohol syndrome. Am $\mathcal{F}$ Epidemiol 1984;119:301-8.

12 Halmesmäki E. Alcohol counseling of 85 pregnant problem drinkers; effect on drinking and fetal outcome. Br $\mathcal{F}$ Obstet Gynaecol 1987;95:243-7.

13 Rosett HL, Weiner L, Lee A, Zuckerman B, Dooling E, Oppenheimer E. Patterns of alcohol consumption and fetal development. Obstet Gynecol 1983;61:539-46.
14 Autti-Rämö I, Granström M-L. The pscyomotor development during the first year of life of infants exposed to alcohol in various durations. Neuropediatrics 1991;22: 59-64.

15 Autti-Rämö I, Granström M-L. The effect of intrauterine alcohol exposition on early cognitive development. Neuropediatrics 1991;22:203-10.

16 Autti-Rämö I, Korkman $M$, Hilakivi $L$, Lehtonen $M$, Halmesmäki E, Granström M-L. Mental development of 2-year-old children exposed to alcohol in utero. $\mathcal{F}$ Pediatr (in press).

17 Hamesmäki E, Autti IU, Granström M-L, Stenman U-H. Estradiol estriol, progesterone, prolactin, and human chorionic gonadotropin in pregnant women with alcohol abuse. F Clin Endocrinol Metab 1987;64:153-6.

18 Halmesmäki E, Raivio K, Ylikorkala O. Patterns of alcohol consumption during pregnancy. Obstet Gynecol 1987;69: consumpt.

19 Jones KL. Smith's recognizable patterns of human malformation. Philadelphia: W B Saunders, 1988.

20 Penrose LS. Memorandum on dermatoglyphic nomenclature. Birth Defects 1968;IV:1-12.

21 Gaily E, Granström M-L, Hiilesmaa V, Bardy A. Minor anomalies in offspring of epileptic mothers. $\mathcal{F}$ Pediatr 1988; 112:520-9.

22 Marden PM, Smith DW, McDonald MJ. Congenital anomalies in the newborn infant, including minor variations. F Pediatr 1964;64:357-71.

23 Leppig KA, Werler MM, Cann CI, Cook CA, Holmes LB. Predictive value of minor anomalies. I. Association with major malformations. F Pediatr 1987;110:531-7.

24 Bayley N. Manual for the Bayley scales of infant development. New York: Psychological Corporation, 1969.

25 Reynell J. Manual for the Reynell developmental language scales (revised). Merseyside: John Gardner Ltd, 1977.

26 Dixon WJ, Brown MB, Engelman L, et al, eds. BMDP statistical software. Berkeley, CA: University of California Press, 1988 .

27 Day NL, Richardson G, Robles N, et al. Effect of prenatal alcohol exposure on growth and morphology of offspring at 8 months of age. Pediatrics 1990;85:748-52.

28 Tennes K, Blackard C. Maternal alcohol consumption, birth weight, and minor physical anomalies. Am $\mathcal{F}$ Obstet Gynecol 1980;138:774-80.

29 Waldrop MF, Halverson CF. Minor physical anomalies and hyperactive behaviour in young children. In: Hellmuth J, ed. Exceptional infant. Vol 2. New York: Brunnel-Mazel, 1971:343-80.

30 Quinn PO, Rapoport JL. Minor physical anomalies and neurologic status in hyperactive boys. Pediatrics 1974;53: 742-7.

31 Firestone $\mathbf{P}$, Teres S, Rivier $\mathbf{M}$. Minor physical anomalies in hyperactive, retarded and normal children and their hyperactive, retarded and normal children and their

32 Lindahl E, Michelsson K. Neurodevelopmental significance of minor and major congenital anomalies in neonatal high risk children. Neuropediatrics 1986;17:86-93.

33 Spranger J, Benirschke K, Hall JG, et al. Errors in morphogenesis: concepts and terms. F Pediatr 1982;100:160-5. 4 Cohen MM. The child with multiple birth defects. New York: Raven Press, 1982:18-21.

35 Frias JL, Wilson AL, King GJ. Acephalometric study of fetal alcohol syndrome. $\mathcal{F}$ Pediatr 1982;101:870-3.

36 Jones KL, Hanson JW, Smith DW. Palpebral fissure size in newborn infants. F Pediatr 1978;92:787.

37 Bierich JR, Majewski F, Michaelis R, Tillner I. Ueber das Embryo-fetale Alkoholsyndrom. Eur 7 Pediatr 1976;12: 155-77.

38 Fuchs $M$, Isoub S, Bingol N, Gromisch D. Palpebral fissure size revisited. $\mathcal{f}$ Pediatr 1980;96:77-8.

39 Stengel-Rutkowski S, Schimanek P, Wernheimer A. Anthropometric definitions of dysmorphic facial signs. Hum Genet 1984;64:272-95.

40 Clarren SK, Sampson PD, Larsen J, et al. Facial effects of fetal alcohol exposure: assessment by photographs and morphometric analysis. Am f Med Genet 1987;26:651-66. 